\title{
TEXTOS POETIGOS*
}

\section{Braulio Arenas Miguel Arteche Efrain Barquero Humberto Diaz Casanueva Mario Ferrero Vicente Gerbasi Pedro Lastra Hugo Lindo Venancio Lisboa Eliana Navarro Luis Oyarzuin Nicanor Parra Gonzalo Rojas Ximena Sepúlveda Claudio Solar José Miguel Vicuña}

\section{Braulio Arenas \\ NUEVOS PORMENORES}

Y esto iba a seguir como en un sueño

Como si el sueño mismo se redujera a pájaro

Bien miradas las cosas ninguno de los interlocutores podrían tener una idea exacta de la vida

Todo pasó como un celaje largo

Los dias y las noches pasaron estrepitosamente

Y el sueño reducido a pájaro se redujo a selva

Mientras los dos interlocutores se reducian a hombre y mujer como todos los dias y las noches.

\section{Miguel Arteche}

\section{GOLGOTA}

Cristo, cerviz de noche, tu cabeza al vicrnes otra vez, de nuevo al muerto que volverás a ser, cordero abierto, donde la eternidad del clavo empieza.

Ojos que al estertor de la tristeza se van, ya se nos van. ¿̨Hasta qué puerto?

* Los poemas siguientes fueron leídos por sus autores en sesiones especiales de los Encuentros 
Toda la sed del mundo te ha cubierto, y de abandono toda tu pobreza.

No sé cómo llamarte ni qué nombre te voy a dar, si somos sólo un hombre los dos, en este viernes de tu nada.

Y siento en mi costado todo el frío, y en tu abandono, a solas, hijo mío, toda mi carne en ti crucificada.

\section{Efrain Barquero}

\section{ME AYUDAS}

Me ayudas a esperar un nuevo dia, no como aquellas estrellas lejanas que a veces anuncian el buen tiempo, ni como esas golondrinas pasajeras, o como esta flor que se abre un rato.

Me ayudas con una dulzura de hierro, me ayudas con un aroma permanente, y tu cabellera no se apaga como el fuego, y tu boca no se seca como el agua, y tus ojos no se cierran como el cielo.

Me ayudas con más fuerza que una estrella, y tu bandada no se ausenta ni se muere, $y$ tu trigo se da por todo el año, y tu corazón permanece siempre verde, y tu mariposa nunca se deshace.

Me ayudas, no con el ánimo cambiante del mar o de la tierra, sino como la ola más pura o la cosecha sin sequía. 